\title{
Entre dos crisis económicas. Estrategias de los rumanos en el mercado de trabajo español ${ }^{1}$
}

\author{
Rafael VIRUELA \\ Departament de Geografia-Uiversitat de València \\ raviruel@uv.es
}

Recibido: 08-02-2013

Aceptado: 28-05-2013

\begin{abstract}
Resumen: La crisis económica y financiera global castiga con especial dureza al mercado de trabajo español y ha truncado la trayectoria laboral de un gran número de inmigrantes que, de pronto, se han visto abocados a la precariedad que caracterizó los primeros años de estancia en España. El objetivo de este artículo es analizar las pautas de inserción de los rumanos en el mercado de trabajo español, sus trayectorias laborales y las estrategias que están adoptando en las actuales circunstancias. Algunos se han ido, pero la mayoría está sorteando la crisis aquí. La alternativa a quedarse o marcharse es el retorno parcial. Los resultados de este trabajo proceden de medio centenar de entrevistas a ciudadanos rumanos, que se realizaron en España, en el primer trimestre de 2011, y en una localidad de Rumania, en el mes de abril del mismo año. La información cualitativa se completa con los datos socioeconómicos más relevantes que proporcionan el Instituto Nacional de Estadística y el Ministerio de Empleo y Seguridad Social.
\end{abstract}

Palabras claves: España, inmigración rumana, trayectorias laborales, crisis económica, estrategias anticrisis

${ }^{1}$ Este documento recoge parte del trabajo realizado por el autor en la ejecución del proyecto I+D+i Migraciones de la Europa del Este a España en el contexto geopolítico fronterizo: movilidad circulatoria y retorno, financiado por el Ministerio de Ciencia e Innovación (Ref. CSO2010-14870, 2011-2013). 


\title{
Between two Economic Crises. Strategies of Romanians in the Spanish Labour Market
}

\begin{abstract}
The global financial and economic crisis has hit the Spanish labour market particularly hard and has ended the working lives of a large number of immigrants who have suddenly been pushed back into the insecurity that characterized their first years in Spain. The aim of this paper is to analyse the patterns of entry of Romanians into the Spanish labour market, their careers and the strategies that they are adopting in the present circumstances. Some have left, but most are weathering the crisis here. The alternative to staying or leaving is partial return. The results of this study are based on fifty interviews with Romanians, which took place in Spain in the first quarter of 2011 and in a town in Romania in April of that year. Qualitative information is complemented by relevant economic data provided by the National Institute of Statistics and the Ministry of Employment and Social Security.
\end{abstract}

Key words: Spain, Romanian immigration, work trajectories, economic crisis, anti-crisis strategies.

\section{Referencia normalizada}

Viruela, r. (2013). "Entre dos crisis económicas. Estrategias de los rumanos en el mercado de trabajo español”. Política y Sociedad, Vol.50 Núm. 3 981-1008

Sumario: Introducción: emigrantes rumanos entre dos crisis económicas. 1.Fuentes y metodología. 2.Características y distribución geográfica de la comunidad rumana en España. 3.Inserción laboral de los rumanos en los años de expansión económica. 4.Estrategias de adaptación de los trabajadores rumanos en tiempos de crisis. 5.A modo de conclusión. Bibliografía

Des roumains pensent mériter plus, mais ils ne sont pas sûrs du tout que ce "plus" pourra être acquis en Roumanie. Elle est devenue un pays d'émigrants...

(Lucian Boia, 2003, p. 236).

Estoy preocupado porque no tengo trabajo. Pero me queda la esperanza, espero no perderla, no puedo perderla.

(Ioan, rumano, 52 años, residente en España; 8/2/2011)

\section{Introducción: emigrantes rumanos entre dos crisis económicas}

Las migraciones internacionales han experimentado cambios extraordinarios en los últimos años. Desde el punto de vista espacial, Europa del Este se ha convertido en uno de los mayores focos de emigración económico-laboral del planeta y los países 
mediterráneos se han colocado entre los principales países de inmigración. El flujo entre Rumania y España (de carácter unidireccional) se ha convertido en uno de los más importantes. El desarrollo de esta corriente migratoria se enmarca entre dos grandes crisis. La primera, en la década de 1990, acompañó a la sociedad de los países postcomunistas en su transición a la economía de mercado. La crisis actual tiene carácter global y, con mayor o menor intensidad, afecta a toda Europa.

La transición del socialismo al capitalismo, iniciada en Europa del Este tras la caída del muro de Berlín (el 9 de noviembre de 1989), exigió reformas drásticas en todos los ámbitos de la vida económica y social (privatizaciones, reestructuraciones empresariales, cambios en la legislación y en las políticas fiscales y monetarias, en el mercado de trabajo, en los servicios públicos, etc.) de consecuencias muy negativas en las condiciones de vida de la mayor parte de la población. La crisis económica y social desencadenada ha sido más profunda y prolongada en Rumania que en otros países de la región y entre las consecuencias destacan la drástica reducción de la producción y del empleo, con la desaparición de más de dos millones de puestos de trabajo en la década de 1990, la mayoría en el sector industrial (Viruela, 2006; Popescu, 2006; Boboc y Calavrezo, 2010), el rápido aumento del paro, la elevada inflación, la pérdida de poder adquisitivo de los salarios, el empobrecimiento generalizado, la malnutrición y el aumento espectacular de la desigualdad entre ricos y pobres (Gaspard, 1993; Lhomel, 2004, Unicef, 1999; World Bank, 2002, entre otros). La acelerada degradación de las condiciones de vida hizo de Rumania un país sin oportunidades, por lo que había que buscarlas en el exterior. Como dice Lucian Boia (2003), los rumanos consideran que merecen mucho más de lo que tienen y, como no confían en conseguirlo en Rumania, emigran al extranjero. El flujo se ha dirigido sobre todo a Occidente: Alemania, Austria, Francia, Estados Unidos, Canadá, además de Hungría e Israel (Muntele, 2003). Sin embargo, los países de Europa occidental temían una avalancha incontrolada y adoptaron políticas migratorias restrictivas. Ante las dificultades para instalarse en los países de su preferencia (Alemania, Austria o Francia), los rumanos buscaron otros lugares donde poder trabajar y reorientaron los flujos hacia los países del sur de Europa.

Los rumanos llegaron a España a mediados de la década de 1990 (Şerban y Grigoraş, 2000; Viruela, 2002). Al principio, el país atrajo a pocos inmigrantes (en 1999 había 6.410 residentes), pero pronto se convirtió en uno de los principales destinos. En la actualidad, la comunidad rumana está integrada por unos 900.000 efectivos, que suponen el 16\% de la población extranjera que vive en España. El rápido aumento de la inmigración se relaciona con la amplia oferta de empleo generada por un crecimiento económico extraordinario impulsado por la construcción, los servicios relacionados con el turismo, la consolidación de la agricultura intensiva de exportación y otras actividades de bajo valor añadido. Los inmigrantes han cubierto más de la mitad de los nuevos empleos que se han creado entre los años 2000 y 2007 (Pajares, 2009) y muchos han sido ocupados por ciudadanos rumanos. La teoría de la segmentación del mercado de trabajo (Piore, 1979 y 1983) es fundamental para explicar un flujo migratorio atraído por la abundante oferta de empleo. Como en otras regiones, la incorporación al mercado de trabajo de los 
rumanos y otros inmigrantes es diferente a la de los trabajadores autóctonos. Estos tienen una destacada presencia en empleos con buenos salarios, adecuadas condiciones de trabajo y la posibilidad de promoción laboral, mientras que los extranjeros se concentran sobre todo en ocupaciones menos cualificadas, con elevadas tasas de temporalidad y precariedad, escasas retribuciones y menores perspectivas de mejora laboral (Pérez y Serrano, 2008; Cachón, 2009).

El fuerte desequilibrio entre las necesidades del mercado y las limitaciones de entrada legal ha generado un amplio sector de inmigrantes indocumentados, rasgo crónico en el perfil de la inmigración en España (Arango, 2002). La irregularidad ha sido aceptada por las autoridades, que han cedido ante las presiones de un mercado de trabajo necesitado de mano de obra barata (González, 2010). Antes de que Rumania se incorporara a la Unión Europea (el 1 de enero de 2007), en España había más rumanos en situación irregular que residentes legales (Pajares, 2007). Era el colectivo extranjero con mayor número de inmigrantes irregulares que, pese a las restricciones, han podido entrar, residir y trabajar gracias al apoyo de las redes migratorias. Las redes constituyen uno de los principales factores explicativos de este flujo migratorio (Şerban y Voicu, 2010; Ciobanu, 2010) ya que proporcionan recursos que difícilmente podría lograr el migrante de forma individual (Arango, 2000), aportan información y referencias laborales esenciales para la inserción laboral del inmigrante y reducen el tiempo de búsqueda de trabajo (Massey y García, 1987; Gurak y Caces, 1998). Sendas encuestas llevadas a cabo en las provincias de Madrid y Castellón (Viruela, 2002; Sandu, 2009; Bernat et al., 2010) revelan que la inmensa mayoría tenía familiares y amigos ya asentados en el lugar de destino, que les han ayudado en su incorporación al mercado de trabajo. El proceso ha sido relativamente sencillo: llegan unos, encuentran trabajo, llaman a familiares y amigos, y así sucesivamente.

Aparte de los factores ya comentados, este flujo se ha visto favorecido por factores políticos que, como señala el profesor Arango (2003), tienen hoy más importancia que las diferencias salariales. En este sentido, hay que tener en cuenta que la presencia de ciudadanos rumanos en España experimenta un notable aumento a partir de 2002, año en que la exención de visado (en enero) facilitó la movilidad por Europa occidental y en el que, con el objetivo de prevenir las migraciones clandestinas y la explotación laboral de los trabajadores, España y Rumania firmaron (en diciembre) un acuerdo en materia de inmigración ${ }^{2}$ promovido, como había ocurrido con otros países del Este, por la previsible ampliación de la Unión Europea (Terrón, 2004; Gordo, 2008). El acuerdo ha sido aprovechado por miles de rumanos para incorporarse al mercado de trabajo español con un contrato firmado en origen, un

${ }^{2}$ Acuerdo entre el Reino de España y Rumania relativo a la regulación y ordenación de los flujos migratorios laborales entre ambos Estados. BOE, núm. 289, 3 de diciembre de 2002. 
máximo de 50.000 en el mejor de los años (Şerban y Voicu, 2010), la mayoría para trabajar en tareas agrarias. La incorporación de Rumania a la Unión Europea ha tenido una gran incidencia en esta corriente migratoria: en 2007, el stock de residentes rumanos aumentó en más de 200.000, pese a las restricciones de acceso al mercado de trabajo impuestas a los nuevos ciudadanos comunitarios. El gobierno español decidió una moratoria de dos años a la libre circulación de trabajadores, un periodo durante el cual los rumanos recién llegados no podían trabajar en España como asalariados, pero no necesitaban ningún tipo de autorización para trabajar por cuenta propia ${ }^{3}$. La prohibición no afectaba a los que estaban trabajando aquí antes de 2007 ni a los que estuvieran inscritos en las oficinas de empleo, y tampoco a los que llegaran con un contrato firmado en origen. Dos años después, el consejo de ministros aprobó la supresión de las restricciones, de manera que a partir del 1 de enero de 2009 los rumanos podían desplazarse libremente a España y encontrar trabajo ${ }^{4}$. Sin embargo, ante el progresivo deterioro del mercado de trabajo español y el aumento de la comunidad rumana España, el gobierno decidió reactivar las restricciones en julio de $2011^{5}$. Se trata de una medida excepcional que, en principio, debía finalizar en diciembre de 2012, pero que finalmente puede prorrogarse hasta diciembre de 2013, momento en el que todas las restricciones deben finalizar (European Commission, 2012).

La gran crisis global, iniciada a finales de 2007, tiene efectos severos en la economía española y en el bienestar logrado tras una década de crecimiento sostenido. En un lustro, la recesión se ha llevado por delante más de tres millones de empleos y el número de parados se acerca a los seis millones, lo que equivale al $26 \%$ de la población activa. La crisis afecta más a los inmigrantes, cuya tasa de paro es del 36 '5\%, frente al 24'2\% de los españoles. El colectivo rumano es uno de los más perjudicados (European Commission, 2012), lo que se debe a la acusada dependencia del sector de la construcción, el más golpeado por la recesión económica, y por su confinamiento en trabajos de baja cualificación y la mayor tasa de temporalidad (García y Troncoso, 2011).

\footnotetext{
${ }^{3}$ Véase: Commission of the European Communities, COM 2008, 765 final, <http://eurlex.europa.eu/LexUriServ/LexUriServ.do?uri=COM:2008:0765:FIN:EN:PDF> [22 de septiembre de 2012].

${ }^{4}$ Véase la Instrucción DGI/SGRJ/01/2009 sobre el levantamiento de las restricciones a la libre circulación de los trabajadores asalariados nacionales de los dos Estados que se incorporaron a la Unión Europea el 1 de enero de 2007, y de los familiares de aquellos, $<$ http://extranjeros.empleo.gob.es/es/NormativaJurisprudencia/Nacional/RegimenExtranjeri a/InstruccionesDGI/documentos/2009/INSTRUCCION_1-2009.pdf > [29 de enero de 2013]

${ }^{5}$ Véase el Boletín Oficial del Estado ${ }^{\circ}$ 176, de 23 de julio de 2011, y la nota de prensa de la Comisión Europea: <http://europa.eu/rapid/press-release_IP-11-960_es.htm> [28 de enero de 2013].
} 
En España, el panorama económico y social es desolador. El paro aumenta con rapidez y supera en más del doble la media comunitaria, y todo indica que seguirá aumentando durante el año 2013. Con el aumento del desempleo y el deterioro de las condiciones de trabajo aumenta la pobreza y los procesos de exclusión social (Laparra y Pérez, 2012). La recesión ha truncado las expectativas de miles de inmigrantes. Sin embargo, pese a la reducción del empleo y las escasas oportunidades de trabajo, no se ha producido el retorno que se había previsto. De momento, la mayor parte de los inmigrantes y sus familias están afrontando la crisis aquí y adoptan diversas estrategias para minimizar sus efectos, como hacen los emigrantes en otros países (Sirkeci et al., 2012).

El objetivo de este artículo es analizar las pautas de inserción de los rumanos en el mercado de trabajo español, sus trayectorias laborales, y las estrategias que están adoptando para hacer frente a la grave crisis que afecta a la economía española.

\section{Fuentes y metodología}

Para la elaboración de este artículo se han combinado la metodología cualitativa y la cuantitativa. Se han aprovechado los resultados de medio centenar de entrevistas en profundidad (entre una hora y hora y media de duración, aproximadamente) a ciudadanos rumanos. La mayoría de las entrevistas se han realizado en España, en el primer trimestre de 2011: 10 en Castellón y 31 en Madrid y municipios de su área metropolitana (Coslada, Alacalá de Henares, etc.), que se encuentran entre los principales lugares de asentamiento. Entre las personas entrevistadas, hay 25 varones y 16 mujeres, con mayor proporción de las edades comprendidas entre 34 y 44 años. En cuanto al estado civil, 19 están casadas, 6 se han divorciado y 14 permanecen solteras, el resto vive en pareja o no contesta. El nivel de formación de los entrevistados es elevado (más entre las mujeres), 15 son licenciados o graduados universitarios, 17 han estudiado bachillerato o formación técnica y profesional, y el resto no ha pasado del nivel de estudios básicos (enseñanza primaria). La mayoría reside en España desde antes de 2007, el año de la incorporación de Rumania a la Unión Europea. Siete se han insertado en la movilidad y se desplazan con relativa frecuencia entre el lugar de origen y el de destino. Algunos entrevistados forman parte del reducido grupo de pioneros que llegó a España en los primeros años 1990. Asimismo, a finales de abril de 2011, se entrevistó a 12 emigrantes retornados y a 6 vecinos del municipio de Tiganesti con familiares emigrados en España, además de personas con cargos relevantes (el alcalde, una maestra, el director de un colegio, un cura ortodoxo y un pastor adventista) en esta localidad del departamento de Teleorman (uno de los que envía más emigrantes a España).

La técnica de acceso a las personas entrevistadas consiste en los contactos enlazados o de "bola de nieve", comenzando por alguien conocido por el entrevistador. A partir de ahí se van efectuando otros contactos sugeridos o propiciados por el anterior. Las preguntas incluidas en las entrevistas giran en torno a una gran variedad de temas, que nos aproximan a la vivencia, experiencia y estrategias de los 
inmigrantes. Una vez transcritas las entrevistas, los contenidos se agrupan por grandes bloques temáticos mediante la aplicación del programa de codificación ATLAS.ti. Para este artículo se han aprovechado las cuestiones que hacen referencia a la inserción en el mercado de trabajo español, las trayectorias laborales y la situación en el momento de la entrevista, lo que permite evaluar el alcance de la crisis y las estrategias adoptadas por los entrevistados.

La información cualitativa se completa con los datos socioeconómicos más relevantes que proporcionan el Instituto Nacional de Estadística (INE) y el Ministerio de Empleo y Seguridad Social (MESS). Del primero destaca el Padrón de Habitantes, que se actualiza cada año y donde figuran las personas que residen en los más de 8.000 municipios españoles. Constituye la fuente estadística más apropiada para conocer el número de efectivos, la edad, el sexo y su distribución geográfica, ya que los extranjeros, incluidos los que se encuentran en situación irregular, tienen tendencia a registrarse para obtener ciertas ventajas, como el acceso a los servicios sanitarios y educativos, o el certificado de residencia que resulta indispensable en los procesos de regularización. Otros datos proceden de la Estadística de Variaciones Residenciales, que elabora el INE con las altas y bajas registradas en el Padrón y que recoge los cambios de residencia a lo largo de un año, lo que permite analizar (con limitaciones) la movilidad geográfica en España y los flujos migratorios con el exterior. Por su parte, la base de datos de la Seguridad Social (MESS) proporciona información de la inserción laboral de los extranjeros, según el régimen de cotización: el general (la mayoría son asalariados de la industria y los servicios) y los regímenes especiales (el agrario, el del mar, el de la minería del carbón, el de los empleados de hogar y el de trabajadores autónomos). Aunque se han detectado algunas irregularidades (por ejemplo, personas que cotizan sin trabajar o personas que cotizan en un régimen distinto al de trabajo), constituye una fuente fiable, pero solo aporta información de los trabajadores que tienen un contrato en regla y no incluye a los inmigrantes nacionalizados, que aparecen como españoles.

El análisis de los resultados se inserta en el marco de los estudios que se han venido realizando en los últimos años sobre la inmigración de Europa del Este en España y en particular sobre la migración rumana, entre los que destacan los trabajos de sociólogos rumanos (Şerban y Grigoraş, 2000; Şerban y Voicu, 2010; y Sandu, 2009), geógrafos (Marcu, 2011; Viruela, 2011) y economistas y sociólogos españoles (Bernat et al., 2010; Bernat y Viruela, 2011), entre otros.

\section{Características y distribución geográfica de la comunidad rumana en España}

La comunidad rumana residente en España se caracteriza por la concentración de efectivos en los grupos de edad intermedio, el 54'4\% tiene entre 20 y 40 años, cuando esta proporción es del 26'7\% entre los españoles. Las posiciones se invierten en el grupo de 65 años y más, que reúne al 19\% de los autóctonos y a menos del 1\% de los rumanos. Se trata de una población joven, con elevada representación en los 
grupos de edad más activos, como corresponde a una inmigración laboral, cuya tasa de actividad (el 84,5\%, en 2011) es de las más altas, lo que se deriva de su condición inmigrante, de su particular estructura por edad y de la elevada participación de la mujer en el trabajo remunerado. Esta inmigración ha sido desde sus inicios un flujo de hombres y mujeres (Viruela, 2002) y ha reafirmado su carácter familiar en los últimos años. Los varones tenían mayor protagonismo al principio (más del 61\% en 2001), en relación con factores culturales en origen que les asigna el rol de principal proveedor de recursos para la familia, pero también con las oportunidades económico-laborales en destino, donde la construcción permite obtener ingresos elevados. La reducción de las diferencias entre sexos (en la actualidad los varones suponen el 51'6\%) obedece fundamentalmente a procesos de reagrupación familiar y a la demanda de mano de obra para trabajos reproductivos. Es habitual que trabajen todos los miembros de la familia en edad laboral:

Los rumanos trabajamos sin papeles, en el mercado negro. Nos registramos solo en el Ayuntamiento para tener lo del Padrón. Yo trabajé todo el año y mi hijo también trabaja en construcciones. Y la hija trabaja en casas, para ella es más fácil... tiene mucho trabajo, trabaja en varias familias. Mi mujer también trabajó algunas horas en algunas casas (Varón, 61 años, retornado en 2004).

El volumen alcanzado por esta corriente inmigratoria (cerca de 900.000 personas en enero de 2012) ha estado acompañado de un rápido proceso de difusión territorial a partir de los primeros lugares de asentamiento: Madrid, Zaragoza y Castellón (figura 1). No obstante, la distribución geográfica se caracteriza por la concentración en tres grandes áreas que tienen como centro a estas localidades. La primera corresponde al área metropolitana de Madrid y se prolonga por las regiones limítrofes, en especial por el sur, en Castilla-la Mancha. En segundo lugar destaca el litoral oriental y meridional, con mayor número de efectivos en el distrito de la industria cerámica de Castellón, y las comarcas de agricultura intensiva de Almería y Huelva. El tercer eje de concentración se extiende a lo largo del valle del Ebro, en especial por Aragón, que ha registrado un notable incremento de inmigrantes rumanos que llegaron atraídos por las oportunidades de empleo en el sector de la construcción que generó la Exposición de 2008 y por la oferta de empleo en tareas agrarias. A estas tres áreas de concentración se ha sumado desde hace poco la que se extiende a lo largo del valle del Guadalquivir. 
Figura 1: Distribución geográfica de los residentes rumanos por municipios, en 2001 y 2012
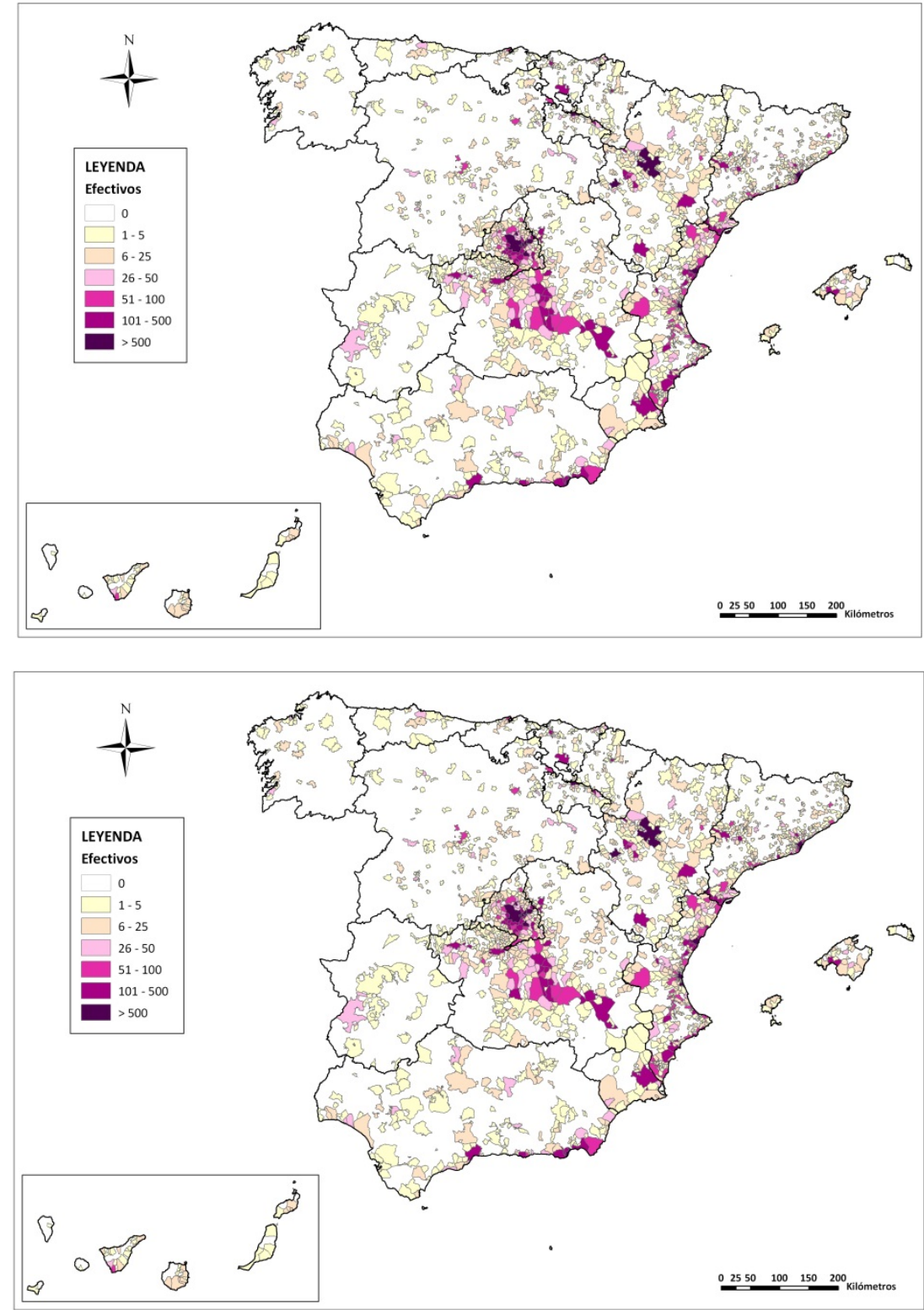

Fuente: INE: Censo de Población y Viviendas 2001 (noviembre) y Padrón de Habitantes en 2012 (enero). 
La distribución geográfica de los rumanos, como la de otros grupos de inmigrantes, coincide a grandes rasgos con la de la población española y el dinamismo económico, y se relaciona con la oferta de empleo, más amplia y diversificada (construcción, servicio doméstico, industrias manufactureras, agricultura intensiva de regadío, actividades relacionadas con el turismo, etc.) en las áreas urbanas y litorales. Pero, a diferencia de otros colectivos, los rumanos manifiestan cierto interés por municipios pequeños. Según el Padrón de 2012, el 25\% vive en localidades que no superan los 10.000 habitantes de censo, que hasta hace poco tenían escaso atractivo para los inmigrantes porque aquí resulta más difícil encontrar trabajo:

Los primeros ocho meses fueron muy duros y empecé a preguntar. Como se trata de un pueblo, era difícil encontrar casas para limpiar (Mujer, de 56 años, retornada en 2010).

Aparte de la oferta de empleo, la distribución geográfica se relaciona fundamentalmente con la presencia de familiares, amigos o compatriotas que dan seguridad al recién llegado y le ayudan en el proceso de inserción sociolaboral. Los rumanos que residen en Castellón, Madrid y su área metropolitana reconocen que:

Hay un gran número de personas [de su misma nacionalidad]. Parece Rumania, vas por la calle y encuentras rumanos y oyes más el rumano que el español, y hay ciertos lugares en Coslada en los que puedes estar seguro que si vas oyes hablar solo rumano (Mujer, 42 años, traductora e intérprete).

\section{Inserción laboral de los rumanos en los años de expansión económica}

La mayor parte de los entrevistados ha iniciado su trayectoria laboral en España en la economía sumergida con el apoyo de las redes migratorias. El procedimiento habitual ha consistido en entrar de forma legal como turista (hasta enero de 2007) y trabajar como inmigrantes irregulares gracias a la información, intermediación y referencias laborales que proporcionan familiares y compatriotas. Hemos entrevistado a rumanos que llegaron en fin de semana y el lunes se pusieron a trabajar. En estos casos, la decisión de emigrar se toma cuando se tiene la certeza de que contarán con el apoyo necesario en el lugar de destino (Ciobanu, 2010). Algunos han migrado en solitario, circunstancia más propia de los calificados como pioneros, para los que es fundamental la ayuda que les proporciona la población autóctona (Domingo y Viruela, 2001).

\subsection{Las puertas de entrada al mercado de trabajo}

Se puede decir que los rumanos han venido a España para trabajar en la construcción (los varones) y en el servicio doméstico (las mujeres). En efecto, según la Encuesta Nacional a Inmigrantes de 2007, ambos sectores ocupaban al 61 y al 47\% de los trabajadores, respectivamente, de uno y otro sexo (colectivo Ioé y Fernández, 2010). Las entrevistas realizadas en Madrid y Castellón muestran la importancia 
que han tenido estos sectores en el momento de la llegada a España (figura 2). Para las mujeres "resulta difícil encontrar otra cosa" que no sea el servicio doméstico (según los testimonios recogidos). Muchas han empezado en la modalidad de trabajadoras internas, lo que les permite solventar necesidades básicas: la manutención y el primer alojamiento (Marcu, 2009):

Me metí de interna en Madrid y fue un fracaso total, fui muy infeliz con aquella familia..., yo me sentía débil, [pero] me quedé 9 meses... (Mujer, 34 años, desempleada)

Los varones, muchos de ellos con experiencia previa en Rumania, han aprovechado la expansión del sector inmobiliario para su inserción laboral en España. Han predominado los trabajadores asalariados de baja cualificación (peones) y muchos han trabajado para empresarios de su misma nacionalidad (Şerban y Grigoraş, 2000; Viruela, 2002; Pajares, 2007; Sandu, 2009, etc.). Otros se han ocupado en la agricultura, la industria agroalimentaria, la hostelería, etc., pero hay pocos casos entre las personas entrevistadas. No obstante, cabe señalar que la agricultura emplea a un gran número de rumanos, tanto hombres como mujeres (Viruela, 2009).

Figura 2. Estructura ocupacional de los rumanos entrevistados en el momento de su llegada a España y en el momento de la entrevista

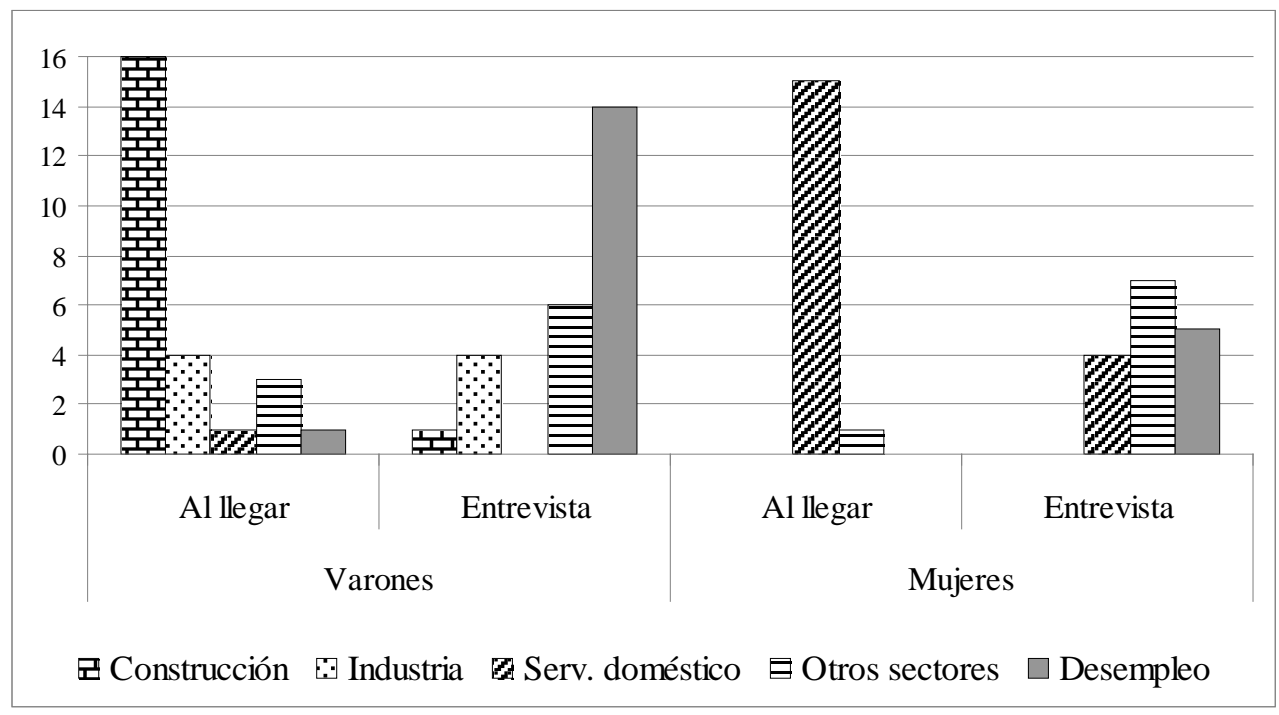

Fuente: Entrevistas, 2011. Elaboración propia

En los primeros años de estancia en España, las expectativas laborales de los rumanos son limitadas por dos motivos. Por un lado, como señalan Gurak y Caces (1998), la red proporciona información y recursos de unas pocas actividades y ocupaciones, en las que hay grandes concentraciones de inmigrantes. Por otro lado, 
el mercado no reconoce la preparación de los recién llegados y les relega a los puestos más bajos de la pirámide laboral (Cachón, 2009), como manifestaba el presidente de la Federación de Asociaciones de Inmigrantes Rumanos en España:

Hoy el rumano tiene unas expectativas laborales muy limitadas pero llegará un momento en que no se conforme con acceder a la escala más baja del proceso productivo. No se le reconoce su preparación. Una de las propuestas que vamos a hacer es que se agilice la homologación de títulos para que esos ingenieros, arquitectos, químicos... rumanos que vienen a España no entren directamente a trabajar en la hostelería o el trabajo doméstico ( $E l$ País, 24 de junio de 2006).

En la primera etapa del proceso migratorio, la de la irregularidad administrativa, las condiciones de trabajo son muy precarias. Las personas entrevistadas se refieren a los bajos salarios, a la alternancia de periodos de intensa actividad con otros de desempleo, a los abusos de que son objeto por parte de los empleadores, aunque sean compatriotas suyos que, con frecuencia, les adeudan cantidades importantes de dinero o no les pagan por sus servicios. Los empresarios se aprovechan de la indefensión jurídica y laboral de los inmigrantes, cuya capacidad de reacción es escasa o nula. Si a ello añadimos el desconocimiento del entorno y del idioma, y los problemas de comunicación con la sociedad de acogida, se comprenderá el sentimiento de frustración, angustia y nostalgia que embarga al recién llegado. El término rumano "dor" (recurrente en las entrevistas) define bien cuál es el estado de ánimo de los recién llegados. De todas las ocupaciones, es el servicio doméstico, en la modalidad de régimen interno, donde son más frecuentes los casos de explotación laboral ya que la trabajadora tiene que estar permanentemente disponible para realizar una gran variedad de tareas, las propias del hogar y el cuidado de niños y personas mayores con problemas físicos y psíquicos:

Trabajé en casas, cuidando niños y gente mayor. Limpiaba, lavaba, planchaba... dormía allí. Estaba a su disposición día y noche. Siempre allí... te toman el pelo, tú no sabes el idioma, te explotan, pero tienes que aguantar. Tenía que trabajar ininterrumpidamente, sin respiro. Me despertaba a las dos de la mañana, porque mi dueña necesitaba compañía... muy difícil (Mujer, de 53 años, que regresó a su país en 2011).

Es habitual que los inmigrantes aprovechen los periodos de desempleo para mejorar su formación. Realizan cursos de informática, idiomas (sobre todo de español), publicidad y marketing, intermediación cultural, peluquería, estética y cosmética, vigilancia y seguridad, asistencia y cuidado de ancianos, etc. Los inmigrantes son pragmáticos y eligen los cursos que les permitan mejorar sus capacidades y habilidades y, de esta forma, ampliar el horizonte laboral. También es frecuente que se desplacen de unas regiones a otras, como han manifestado varios peones de la construcción y jornaleros agrarios, e incluso las empleadas de hogar. La movilidad geográfica de los inmigrantes rumanos es más elevada en los primeros momentos de su estancia en España y responde a la continua búsqueda de oportunidades (Viruela, 2010). 


\subsection{Itinerarios laborales}

Los inmigrantes, como los españoles, no tienen una posición estática en el mercado de trabajo (Cachón, 2009; Torres, 2011). En función de las oportunidades que ofrece el mercado y de las normas legales, los trabajadores intentan mejorar su inserción laboral y social. En lo laboral, el principal objetivo es conseguir empleos con mejores condiciones de trabajo y mayores ingresos, y que resulten más acordes con el nivel de formación y cualificación del trabajador. En términos sociales, lo primordial es alcanzar el estatus legal, que es la condición necesaria para la movilidad laboral ascendente, aunque no siempre resulta suficiente.

Figura 3. Evolución de las altas de trabajadores rumanos en la Seguridad Social y variación anual entre 1998 y 2012

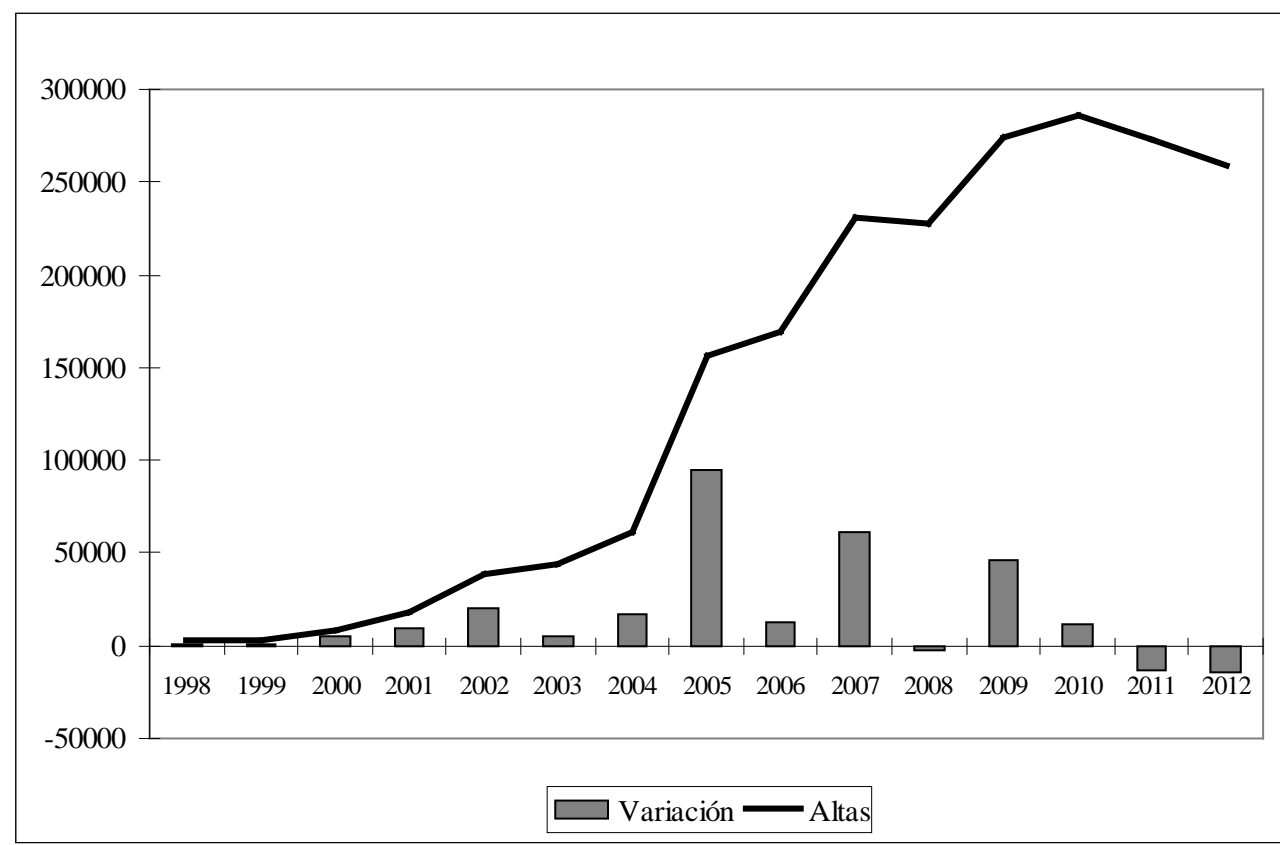

Fuente: Fuente: MESS, Anuario de Estadísticas del Ministerio de Empleo y Seguridad Social, http://www.mtin.es/es/estadisticas/contenidos/anuario.htm, y Estadísticas de la Seguridad Social, http://www.seg-social.es/Internet_1/Estadistica/index.htm

La situación del inmigrante mejora cuando consigue un contrato de trabajo y, afortunadamente, la contratación de trabajadores rumanos se ha generalizado desde principios del siglo XXI (figura 3). En 2001, la Seguridad Social contaba con 18.200 afiliados de nacionalidad rumana; en 2005 eran cerca de 156.000 y en el momento actual son 258.613 (diciembre de 2012). Varios factores han contribuido 
en este súbito y espectacular aumento: los procesos de regularización, en particular el de 2005, que en pocos meses permitió la legalización de 96.000 rumanos en situación irregular, muchos de ellos contratados por familias españolas para tareas domésticas; el acuerdo bilateral entre España y Rumania de 2002 o la incorporación de Rumania a la UE en 2007, ya comentados. Miles de rumanos sortearon las restricciones impuestas por el gobierno español en aquel año incorporándose legalmente al mercado como trabajadores autónomos, cuya cifra pasó de 4.900, en diciembre de 2006, a un máximo de 48.709, en mayo de 2008. En realidad, muchos de ellos trabajaban para otros como asalariados.

La movilidad laboral ascendente depende, entre otros factores, del momento de la llegada a España (en los procesos de regularización, el inmigrante tiene que demostrar el tiempo de residencia), de la experiencia, cualificación y formación, que el inmigrante intenta mejorar durante su estancia, así como de la homologación de títulos, del conocimiento del entorno y del idioma, de las relaciones sociales, etc. (Caparrós y Navarro, 2010; Simón et al., 2011). Los entrevistados destacan la importancia que ha tenido el aprendizaje del español en el éxito de su integración, al igual que los contactos y relaciones con la población autóctona. Los "amigos" españoles presentan el "precontrato" que se exige en los procesos de regularización y proporcionan información y recursos:

La primera experiencia duró tres semanas, en Coslada. Luego tuve que irme. Aprendí el idioma, empecé a tener relaciones con los españoles... un español me dio trabajo, me dio alojamiento gratis, yo trabajé para él, el hombre me pagó. Lo que más valoro es que él me ayudara con el alojamiento. Luego obtuve la residencia (Varón, 62 años, retornado en 2008).

Los factores que se acaban de indicar, junto con la concentración de personas del mismo origen, brindan oportunidades de ascenso y promoción laboral. Así, varios de los entrevistados, a requerimiento de la policía y de los tribunales, han trabajado como traductores de documentos e intérpretes en diversas causas relacionadas con compatriotas y otros extranjeros. Por otro lado, ante la posibilidad de negocio que representa la población extranjera, entidades financieras, compañías de seguros, gestorías y empresas de servicios incorporan inmigrantes en sus plantillas para captar clientes extranjeros. Una forma de lograr el ascenso laboral consiste en trabajar por cuenta propia o como autónomo. Los rumanos han creado un gran número de empresas en España, desde pequeños establecimientos familiares, con pocos operarios, en diversos sectores de actividad: bares y restaurantes, tiendas de comestibles y panaderías, peluquerías y gabinetes de estética, medios de comunicación y transporte, centros de enseñanza y de odontología, etc., hasta empresas que ocupan medio centenar o más de trabajadores, sobre todo en la construcción, que suelen trabajar subcontratadas por las grandes firmas del sector (Bucur, 2012). Sea como fuere, suelen transcurrir varios años hasta que el inmigrante consigue mejorar laboralmente y ocupar un empleo acorde con sus aspiraciones y su nivel de formación:

Comencé a trabajar en el servicio doméstico sin papeles, evidentemente. Luego di un gran salto hacia el trabajo legal, con papeles, con permiso de residencia. Trabajé 
como auxiliar administrativa... y luego, la homologación de mi título, a través del Ministerio, me ofreció la oportunidad de buscar un empleo un poco más próximo a mi especialización (Mujer, 35 años, mediadora intercultural).

Salvo alguna excepción, los entrevistados han cambiado varias veces de trabajo, empresa o familia, sobre todo durante la etapa de irregularidad administrativa porque suelen ocupar empleos temporales u ocasionales, o por desavenencias con el empleador relacionadas con las condiciones de trabajo o con el salario. Este es el principal motivo esgrimido por las mujeres que trabajan en el servicio doméstico y por los peones de la construcción. Algunos inmigrantes también han cambiado de sector de actividad en esta primera fase del proceso migratorio, pero es más frecuente cuando consiguen el estatus legal y casi siempre significa la movilidad laboral ascendente. Por lo general, las mujeres jóvenes y con estudios universitarios abandonan el servicio doméstico para trabajar en la hostelería, el comercio o las actividades administrativas. Varios entrevistados, tanto hombres como mujeres, han encontrado trabajo como mediadores culturales y en la gestión de proyectos en las asociaciones de inmigrantes y en los centros de integración (CEPI), subvencionados por la administración. Algunos trabajadores ascienden dentro del sector de la construcción, pasan de peones a especialistas o empresarios, otros dejan la construcción por la industria, los transportes o el servicio de vigilancia, como ha hecho un inmigrante con diez años de residencia en España, y con varios empleos y contratos en el sector de la construcción:

[Ahora] trabajo por turnos. Mi trabajo consiste en pedir los datos a la gente, aunque esto lo hago menos, lo hacen más los españoles. Yo trabajo más por la noche, vigilando el edificio (Varón, 43 años, vigilante).

Las condiciones generales en las nuevas actividades son mejores que las de los empleos de donde proceden pero, en honor a la verdad, hay que señalar que las condiciones concretas de los puestos que ocupan no son mejores que las de los autóctonos ya que trabajan en turnos nocturnos o vespertinos y, con frecuencia, las tareas que realizan no se corresponden con las de su categoría, en contra de lo estipulado en el contrato de trabajo.

\section{Estrategias de adaptación de los trabajadores rumanos en tiempos de crisis}

La crisis se manifiesta en la destrucción de empleo y en el rápido aumento del paro. El volumen de personas que quieren trabajar y no encuentran dónde hacerlo se acerca a los seis millones y la tasa de paro supera el 26\% de la población activa. Las condiciones de trabajo se deterioran y aumenta el riesgo de pobreza de las personas ocupadas, la sociedad española se fractura y la mayoría de los pronósticos coinciden en que la situación empeorará (Laparra y Pérez, 2012). La crisis afecta sobre todo a la población extranjera, siendo el colectivo rumano uno de los más perjudicados. El número de rumanos inscritos en la Seguridad Social se ha reducido en los dos 
últimos años (véase la figura 3) y según la Encuesta de Población Activa, que también incluye a los que laboran en la economía sumergida, la cifra de ocupados se ha reducido en un $20 \%$ entre 2008 y 2011. En el último año había más de 181.000 personas en situación de desempleo (el 36\% de la población activa), una cifra que solo superan los marroquíes (285.284) y que supone prácticamente el doble de la registrada hace cuatro años. Lo peor de todo es que en el $13 \%$ de los hogares todos sus miembros están en paro (colectivo Ioé, 2012). Las entrevistas realizadas muestran la gran variedad de estrategias adoptadas por los inmigrantes rumanos para mitigar los efectos de la crisis. Sin ánimo de exhaustividad, a continuación se comentan algunos ejemplos.

\subsection{Estrategias laborales}

Cuatro de cada diez personas entrevistadas se han quedado sin empleo, la mayoría varones que han llegado a España en fecha reciente. La diferencia entre sexos se debe a la acusada dependencia de la mano de obra masculina del sector de la construcción, uno de los más golpeados por la recesión económica. En cambio, las mujeres, con mayor presencia en los servicios, muestran mayor resistencia (figura 4). Los entrevistados son conscientes de la gravedad de la crisis y de las dificultades que tienen los parados para reinsertarse al mercado de trabajo, sobre todo las personas de cierta edad. Por este motivo, los miembros de la familia que permanecían inactivos se ponen a trabajar, lo que ha permitido resistir a muchas familias, como ilustra el caso de una mujer de cuarenta años de edad, residente en Castellón, cuyo marido, trabajador de la industria cerámica, se encuentra en paro y cobra la prestación por desempleo:

Yo llevo más de un año trabajando como empleada de hogar porque no veíamos clara la situación. Los 400 euros mensuales que ingreso ayudan mucho a pagar la hipoteca y al mantenimiento de nuestros tres hijos (Las Provincias, 13 de septiembre de 2009). 
Figura 4. Evolución de la ocupación de la población rumana, entre 2005 y 2011

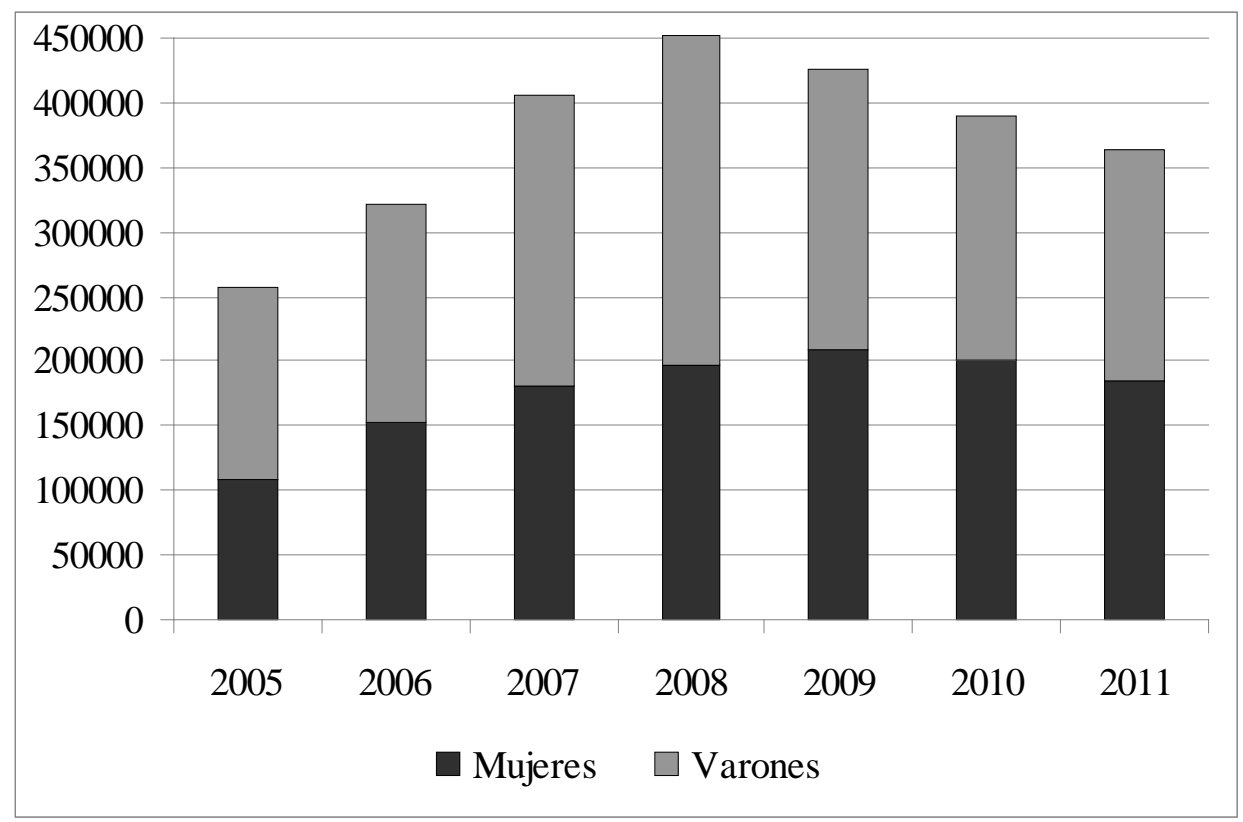

Fuente: Colectivo Ioé (2012), p. 188, con datos del INE: Encuesta de Población Activa

En general, los parados se muestran muy activos en la búsqueda de empleo ("buscar trabajo es un gran trabajo"). El número de rumanos inscritos como demandantes de empleo en las oficinas del Servicio Público de Empleo Estatal ha pasado de 12.700, en 2006, a 95.600, en 2011 (Observatorio de las Ocupaciones), y acuden con más frecuencia a las asociaciones de inmigrantes:

Antes de la crisis atendía a dos personas cada día por término medio que querían información para mejorar su empleo, ahora atiendo a cinco que buscan empleo" (Secretaria de la Asociación Rumana de Castellón).

Sin duda, muchos rumanos viven una situación dramática en España. Sin embargo, la mayor parte de las familias muestra una gran resistencia a la crisis gracias a las prestaciones por desempleo o al salario que aporta alguno de sus miembros, aunque se obtenga en el mercado de trabajo informal (García y Troncoso, 2011). De las entrevistas se deduce que los salarios no han subido o se han reducido y que los trabajadores no se atreven a solicitar aumento de sueldo por temor a que los empleadores prescindan de sus servicios. En las actuales circunstancias, los inmigrantes están dispuestos a aceptar peores condiciones laborales y a trabajar en lo que sea, en la economía sumergida si no hay otra alternativa, con el fin de lograr los necesarios ingresos y así poder resistir: 
Dejé el trabajo [en la agricultura, recogiendo aceitunas] y vine aquí [a Castellón] y mi tío me dio trabajo en el sector de la construcción... justo cuando no había trabajo (se lamenta). Trabajaba donde podía, más de peón, pero no había trabajo. Hoy trabajaba en una cosa, mañana en otra, y así... un poco al día. Desde 2008 trabajo en la Asociación de Inmigrantes de Países del Este, pero más honorífico porque gano poco. De hecho trabajo en un hospital, cuidando a una persona mayor, sobre todo por las tardes y de noche....sobrevivo (Varón, 34 años, coordinador de proyectos AIPE).

Uno de los grupos que se ha visto más afectado por la crisis es el de los trabajadores autónomos. Según las estadísticas de la Seguridad Social, en la actualidad quedan unos 24.000, la mitad de los que se registraron a mediados de 2008 (véase la figura 5). Como se recordará, muchos de ellos se inscribían como autónomos, aunque en realidad trabajaban para otros, para sortear las limitaciones impuestas por un marco institucional discriminatorio (la moratoria impuesta por el gobierno español a los trabajadores por cuenta ajena). Sea como fuere, un gran número de ciudadanos rumanos ha perdido el empleo porque la recesión ha provocado el cierre de un gran número de empresas y negocios, sobre todo los relacionados con la construcción (Bernat y Viruela, 2011). No obstante, hay empresas que están resistiendo bien los embates de la crisis y han surgido nuevas iniciativas, impulsadas precisamente porque resulta difícil encontrar trabajo como asalariado.

\subsection{Estrategias económicas}

Como hacen otros colectivos en dificultades aquí y en otros lugares, los inmigrantes tratan de reducir gastos, en términos de consumo y alojamiento (Torres, 2011; Sirkeci et al., 2012). Así, por ejemplo, algunas mujeres empleadas de hogar han vuelto al régimen interno por el ahorro que supone vivir en casa del empleador, otras se han dado de baja en la Seguridad Social, aunque trabajen igual o más que antes y, de esta forma, se ahorran la cuota correspondiente, aumentando así los recursos disponibles para la familia. Varios entrevistados alquilan habitaciones o comparten la vivienda con otros para afrontar mejor el alquiler o la hipoteca, lo que remite a las condiciones de hacinamiento de los primeros años de estancia en España. De las 41 personas entrevistadas aquí, doce comparten el piso con compatriotas, dos con españoles, uno prefiere no contestar, una mujer vive con su pareja y un hijo de 20 años en un albergue y relata la situación con un lamento desgarrador:

No tengo trabajo, vivo en la Cruz Roja, pronto me quedaré en la calle, estoy desesperada. Y no tengo adonde volver porque tuve muy mala suerte de haber nacido en Rumania. He hecho dos infartos [sic]. Ahora no tengo trabajo, no puedo tranquilizarme... (Mujer, 44 años, desempleada).

Los que se encuentran en una situación más precaria ocupan casas abandonadas y viven en condiciones extremas sin agua ni electricidad (Bucur, 2012) y recurren a las ayudas que proporcionan las parroquias, los servicios sociales y organizaciones como Cáritas o Cruz Roja. Algunos reciben ayuda de familiares que residen en 
Rumania, que les envían parte de los ahorros que fueron transferidos desde España en los años de bonanza. En otros casos, los inmigrantes reagrupan a sus parientes en España para que contribuyan con su trabajo a las rentas familiares o para reducir el envío de remesas, como sugieren Marta Roig y Joaquín Recaño (2012).

\subsection{Estrategias de movilidad}

Los inmigrantes que han perdido el empleo están dispuestos a la movilidad sectorial y geográfica, pero el margen de maniobra es muy limitado por el carácter generalizado de la crisis. En general, se observa una vuelta a la agricultura y al servicio doméstico (figura 5). Ambos sectores han actuado como "puerta de entrada" al mercado de trabajo en la etapa de expansión económica y como "refugio" en tiempos de crisis (Torres, 2011).

Figura 5.- Rumanos afiliados en los regímenes especiales de la Seguridad Social, entre diciembre de 2006 y diciembre de 2012.

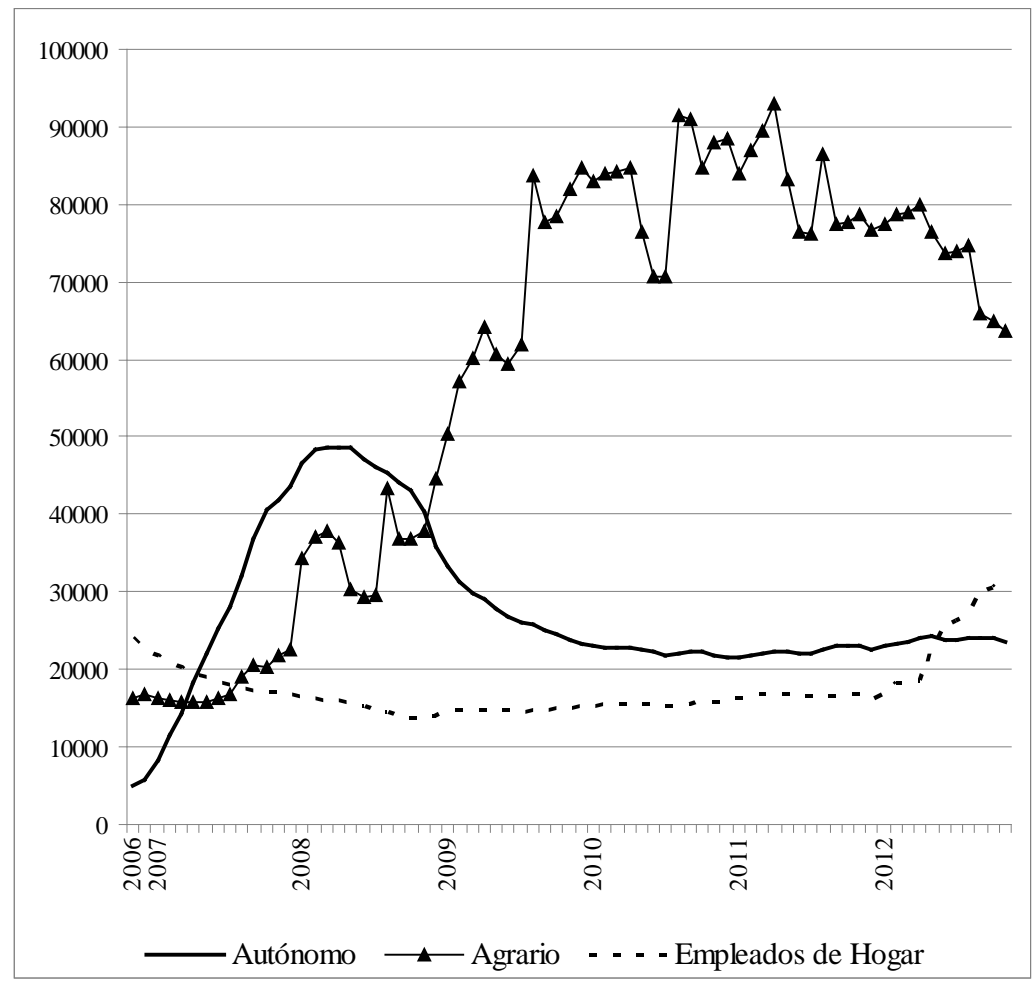

Fuente: Estadísticas de la Seguridad Social:

http://www.seg-social.es/Internet_1/Estadistica/index.htm 
El sector agrario también acoge a trabajadores españoles procedentes de otros sectores de actividad, como se ha constatado en el Campo de Cartagena (Torres y Gadea, 2010), en la provincia de Jaén (Menor, 2011) o en la de Castellón (Bernat y Viruela, 2011), cuyo reclutamiento se basa en las redes familiares y de amistad. El retorno de la mano de obra autóctona a sectores que antes rechazaba es habitual en tiempos difíciles como el actual, como manifestó hace años Michel Piore (1983). Sin embargo, hemos de convenir con Reyneri y Fullin (2011) que en mercados de trabajo tan segmentados como el español, la competencia entre extranjeros y españoles es limitada. En muchas regiones, los empleadores prefieren y siguen contratando trabajadores extranjeros, en muchos casos de nacionalidad rumana (Gualda, 2012). La reciente reducción del número de rumanos afiliados al régimen especial agrario (véase la figura 5) se debe más a la agudización de la crisis que a la competencia entre trabajadores extranjeros o entre estos y los españoles. El aumento de la afiliación de españoles, marroquíes y otros colectivos no comunitarios en el último trimestre de 2012 es modesto y no parece que esté generando procesos de sustitución de unos colectivos por otros.

Otra estrategia es la movilidad geográfica, una posibilidad que contemplan muchos de los entrevistados. Pero, según las Estadísticas de Variaciones Residenciales, los desplazamientos entre municipios y provincias españolas se han reducido desde 2008, así como las entradas procedentes del exterior. Por el contrario, con la crisis aumenta la emigración. Entre 2008 y 2011, se han registrado más de 100.000 salidas de ciudadanos rumanos. En realidad, resulta difícil establecer el volumen exacto de la emigración ya que no todos comunican su partida. Entre los que dan esta información, más del $80 \%$ no indica cuál es el país de destino, el 19\% ha retornado a Rumania, y el resto (menos del 1\%) opta por otros destinos ${ }^{6}$. Varios de los entrevistados manifestaron que preferirían ir a otro país antes que regresar a Rumania:

Estos días he hablado con mi madre y me preguntó si tenía trabajo. Le comenté un poco las perspectivas que tengo y me dijo: si no te va bien en España, vete a cualquier país donde puedes hablar inglés y a ver sí encuentras algo, pero a Rumania no regreses. ¿Volver a Rumania? No, no, antes me voy a cualquier otro país (Mujer, 34 años, estudiante de Filología Inglesa y profesora de rumano).

De las doce personas entrevistadas en la localidad de Tiganesti (Rumania), ocho han retornado en los últimos tres años, coincidiendo con el rápido deterioro del mercado de trabajo en España. Excepto tres desempleados y un jubilado, el resto trabaja en la construcción o en el sector servicios. Algunos han aprovechado la experiencia migratoria para crear su propio negocio. Casi todos han regresado para evitar las consecuencias de la crisis y porque en Rumania es posible subsistir con

${ }^{6}$ Los porcentajes se han obtenido a partir de la información que, amablemente, ha facilitado el profesor Joaquín Recaño, que trabaja con los microdatos de la Encuesta de Variaciones Residenciales. 
menos ingresos, pero no descartan la posibilidad de volver a emigrar, opción que contempla uno de los entrevistados cuya madre reside en España:

Yo trabajaba [en Tiganesti] como vendedor en una empresa de materiales de construcción. Y llevo dos meses sin trabajo. Me iré a España y veré en lo que pueda trabajar. Sé hacer muchas cosas. La región donde está mi madre es agrícola. Me iré a recoger fruta, no tengo miedo al trabajo. Y mi mujer, a lo mejor ayudará a mi madre, a lo mejor encontrará más casas para limpiar (Varón, 33 años, vecino de Tiganesti, desempleado).

Según los resultados de una encuesta realizada en agosto de 2010 en varias localidades rumanas, el 30\% de los retornados pensaba volver a salir antes de seis meses (Stoiciu et al., 2011). El retorno limitado o parcial constituye una estrategia más para enfrentarse a la crisis (Marcu, 2013). Se trata de una modalidad de desplazamiento característica de los migrantes rumanos (Diminescu, 2003; Dumitru et al., 2004; Potot, 2007), que implica frecuentes idas y venidas entre el lugar de origen y el de destino. Según las investigaciones de Silvia Marcu (2011), adquirió notoriedad a partir de 2002, cuando se eximió de visado a los rumanos, y cobró mayor relevancia desde 2009, coincidiendo con el levantamiento de las restricciones a la libre circulación de trabajadores y con el agravamiento de la crisis económica. Estos desplazamientos se aprovechan para realizar trabajos temporales o de corta duración en la construcción, la agricultura, el servicio doméstico, etc. Así lo explica un trabajador de la construcción que, tras perder el empleo, regresó a Rumania con la intención de instalarse por su cuenta y que, ante las dificultades encontradas, ha optado por ir y venir, acompañando a su esposa, que también practica la movilidad:

Trabajé hasta 2008 y luego volví a Rumania, porque se había acabado el trabajo en España. Mi mujer hacía y sigue haciendo lo siguiente: trabaja seis meses en España, cuidando a gente mayor, y vuelve seis meses a Rumania. Es que trabaja por turnos de seis meses con su hermana, cuñada mía... Entonces yo me volví cuando comenzó la crisis y me intenté hacer autónomo en Rumania, pero no funcionó. Y en 2009, me planté otra vez en Madrid... no encontré nada y me fui a Almería de nuevo, y me empleé en la recogida de frutas. Cuando se acabó la temporada en 2009, volví a Rumania, es que de vez en cuando vuelvo, sobre todo cuando coincido con mi mujer, porque tenemos dos hijos. (Varón, 44 años, desempleado).

\section{A modo de conclusión}

Hace algo más de veinte años, la desaparición del comunismo y la apertura de una economía ineficiente liberaron un gran potencial emigratorio en Europa del Este. La pérdida del empleo (más de 2 millones en diez años, que supuso una reducción superior al 20\%), el deterioro de las condiciones de vida, la frustración y la escasa confianza en el futuro han hecho de Rumania uno de los países de mayor emigra- 
ción. Se estima que hay unos tres millones de rumanos fuera de su país ${ }^{7}$ (World Bank, 2010), de los que alrededor de 900.000 residen en España. Este flujo es un claro ejemplo de proceso migratorio basado en las redes, que se ha beneficiado de las decisiones político-administrativas en la gestión de las migraciones, que han favorecido a los ciudadanos de países que acabarían integrándose en la Unión Europea, un espacio en el que la movilidad interior resulta muy fácil (Terrón, 2004). $\mathrm{Ni}$ siquiera las restricciones de acceso al mercado de trabajo, que impuso el gobierno español en enero de 2007 (para un periodo de dos años) y en julio de 2011, han impedido que los rumanos pudieran trabajar, ya que la alternativa al trabajo por cuenta ajena ha sido el trabajo autónomo o en la economía sumergida, como ha ocurrido en otros países que aplicaron este tipo de medidas (European Commission, 2011).

Como en otros países (IOM, 2008), los rumanos han llegado a España para trabajar en la agricultura, la construcción y el servicio doméstico, y han ocupado empleos de baja cualificación, penosos y mal pagados, en el sector secundario de un mercado de trabajo dual, lo que se debe a su condición de trabajadores inmigrantes ya que, según las entrevistas realizadas, su nivel de cualificación e instrucción es elevado. Muchos de ellos han transitado por diferentes ocupaciones y sectores de actividad hasta lograr la movilidad laboral ascendente en los últimos años del boom económico. Diversos factores han contribuido a mejorar la situación sociolaboral: los procesos de regularización documental, la experiencia, el aprendizaje del español o la ayuda de la población autóctona, que no forma parte del círculo de relaciones más íntimo del inmigrante. El apoyo de la red de familiares y compatriotas ha sido fundamental en los primeros momentos de la aventura migratoria, cuando mayor es la incertidumbre, como destacaron hace más de veinte años los estudios de Mónica Şerban y Vlad Grigoraş (2000).

La crisis económica y financiera internacional, iniciada a finales de 2007, ha tenido consecuencias dramáticas para España, cuyo modelo económico ha quedado seriamente cuestionado. En un lustro han desaparecido 3'5 millones de empleos, muchos de ellos ocupados por rumanos, cuya tasa de paro equivale al 36\% de la población activa (European Commission, 2012). La crisis ha truncado la trayectoria laboral de un gran número de inmigrantes, que se han visto abocados a unas condiciones de trabajo similares a las de los primeros años de estancia en España. Las circunstancias actuales son incluso peores debido al progresivo deterioro del mercado de trabajo y al carácter estructural de la crisis. Los salarios disminuyen desde niveles que antes de la crisis ya eran bajos y aumenta el trabajo en la economía sumergida. Los rumanos tienen una larga experiencia en este sentido ya que, antes

7 Véase a este respecto «3 milioane de români, la muncă în străinătate », $<$ http://www.jurnalul.ro/stire-special/3-milioane-de-romani-la-munca-in-strainatate-528860.html> [21 de enero de 2012]. 
de la incorporación de Rumania en la UE (en 2007), en España había más inmigrantes irregulares que residentes legales.

Las crisis inciden directamente en los flujos migratorios. Desde 2008, las entradas de ciudadanos rumanos disminuyen y las salidas aumentan. Sin embargo, a diferencia de lo ocurrido en Rumania hace veinte años, cuando la emigración se convirtió en una "enfermedad" contagiosa, en la actualidad la mayoría de los migrantes permanece en el lugar de destino. Esto es así porque la crisis de la transición afectó a los países poscomunistas, al tiempo que la economía iniciaba una fase expansiva en Occidente, en especial en España. En cambio, la crisis actual es global y las oportunidades de empleo disminuyen aquí y allí.

De momento, pese a la reducción del empleo y el progresivo deterioro del mercado de trabajo en España, la reacción migratoria ha sido más bien una respuesta silenciosa, con retornos limitados, como ha ocurrido en otros países de acogida (King, 2012; Sirkeci et al., 2012), aunque puede que hayan emigrado muchos más de los que constan porque se van y no lo comunican en las oficinas de estadística de la localidad de residencia. Quienes permanecen aquí diversifican las estrategias para minimizar los efectos de la crisis: aceptan salarios más bajos, están dispuestos a trabajar en la economía sumergida y a la movilidad sectorial y geográfica. Otras estrategias de supervivencia pasan por reducir gastos, ahorrar lo que se pueda en el consumo, en la vivienda, etc. Asimismo, las ayudas económicas y los servicios que proporciona el estado de bienestar (prestaciones por desempleo, asistencia sanitaria de calidad, ayudas económicas del sistema educativo, etc.) condicionan la decisión de permanecer en España (Bernat y Viruela, 2011).

La alternativa a permanecer en España o retornar a Rumania, es la movilidad entre un país y otro. En las actuales circunstancias resulta difícil planificar el futuro en un solo lugar, por lo que muchos optan por desplazarse con relativa frecuencia entre el lugar de origen y el de destino, una modalidad de desplazamiento que los rumanos practican desde hace años y que ha cobrado impulso por la crisis, el abaratamiento de los medios de comunicación y de transporte, y por la facilidad de movimientos en el espacio comunitario. Los rumanos, al igual que los nacionales de otros países de la UE, pueden desplazarse libremente y aprovechan las idas y venidas para explorar las oportunidades laborales aquí y allí. 


\section{Bibliografía}

Arango, J. (2000): “Explaining Migration. A Critical View”, International Social Science Journal, vol. 52, $\mathrm{n}^{\circ}$ 3, p. 283-296.

Arango, J. (2002): "La fisionomía de la inmigración en España”, El Campo de las Ciencias y las Artes, $\mathrm{n}^{\circ}$ 139, p. 237-262.

Arango, J. (2003): "La explicación teórica de las migraciones: luz y sombra", Migración y Desarrollo, $\mathrm{n}^{\circ}$ 1, p. 1-30.

Bernat, J. S.; agost, $\mathrm{M}^{\mathrm{a}}$. R.; fuertes, A. $\mathrm{M}^{\mathrm{a}}$.; fuertes, I.; montañes, C.; bucur, R. y soto, G. (2010): Estudio del capital social a partir de las redes sociales y su contribución al desarrollo socioeconómico: el colectivo de inmigrantes rumanos en la provincia de Castellón, Cuadernos de Investigación, $\mathrm{n}^{0} 13$. Valencia, Ceimigra, Tirant lo Blanc.

Bernat, J. S. y viruela, R. (2011): "The Economic Crisis and Immigration: Romanian Citizens in the Ceramic Tile District of Castelló (Spain)”, Journal of Urban and Regional Analysis, vol. 3, $\mathrm{n}^{0}$ 1, p. 45-65, $<$ http://www.jurareview.ro/2011_1_1/a_2011_1_1.htm> [14 de julio de 2012].

Boboc, C. y Calavrezo, O. (2010): "La transition postcommuniste en Roumanie: Quelles évolutions sur le marché du travail”, Cahiers Lillois d'Économie et de Sociologie, $\mathrm{n}^{\circ}$ hors série, p. 147-171.

BOE (2011): Ministerio de Presidencia, Orden PRE/2072/2011. Boletín Oficial del Estado, no 176 , p. 82362-82363.

Boia, L. (2003): La Roumanie. Un pays à la frontière de l'Europe. Paris, Les Belles Letres.

Bucur, R. (2012): Réseaux migratoires roumains en Espagne. Stratégies et territoires de vie à Castellón de la Plana (Comunidad Valenciana). Thèse de Doctorat. Université d'Angers. Directeurs Joan Serafí Bernat et Jean Baptiste Humeau.

Cachón, L. (2009): La España inmigrante: marco discriminatorio, mercado de trabajo y políticas de integración. Barcelona, Antrophos.

Caparrós, A. y Navarro, M ${ }^{\mathrm{a}}$ L. (2010): "Movilidad ocupacional de los inmigrantes en España”, Investigaciones de Economía de la Educación n ${ }^{0}$ 5, p. 873-890. $<$ http://2010.economicsofeducation.com/user/pdfsesiones/072.pdf $>$ [11 de junio de 2012].

Ciobanu, R. O. (2010): "The Thin Line Between Family Migration and Network Migration. Family Stories of the Romanian Migration to Spain”, Revue d'Études Comparatives Est-Ouest, 2010, vol. 41, nº4, p. 125-148.

Colectivo Ioé (2012): Impactos de la crisis sobre la población inmigrante, Organización Internacional para las Migraciones, $<$ http://www.colectivoioe.org/index.php/publicaciones_libros/show/id/101> [30 de noviembre de 2012].

Colectivo Ioé y Fernández, M. (2010): Encuesta Nacional de Inmigrantes 2007: el mercado de trabajo y las redes sociales de los inmigrantes. Madrid, Observatorio Permanente de la Inmigración. 
COMMISSION OF THE EUROPEAN COMMUNITIES (2008): The impact of free movement of workers in the context of EU enlargement, COM (2008) 765 final, $<$ http://eur-

lex.europa.eu/LexUriServ/LexUriServ.do?uri=COM:2008:0765:FIN:EN:PDF> [22 de septiembre de 2012].

Diminescu, D. - dir.- (2003): Visibles mais peu nombreux. Les circulations migratoires roumaines. París, Éditions de la Maison des Sciences de l’Homme.

Domingo, C. y Viruela, R. (2001): “Cadenas y redes en el proceso migratorio español”, Scripta Nova. Revista Electrónica de Geografía y Ciencias Sociales, n 94 (8), <http://www.ub.es/geocrit/sn-94-8.htm> [13 de diciembre de 2012].

Dumitru, M., Diminescu, D. y Lazea, V. (2004): Dezvoltarea rurala si reforma agriculturii românesti, Centrul Roman de Politici Economice, <http://www.ier.ro/index.php/site/page/working_papers> [8 de enero de 2013].

EUROPEAN COMMISSION (2011): Report from the Commission to the Council on the Functioning of the Transitional Arrangements on Free Movement of Workers from Bulgaria and Romania, Brussels, COM (2011) 729 final, $<$ http://ec.europa.eu/social/BlobServlet?docId=7204\&langId=en > [8 de enero de 2013].

EUROPEAN COMMISSION (2012): Commission Decision of 20 December 2012 authorising Spain to extend the temporary suspension of the application of Articles 1 to 6 of Regulation (EU) No 492/2011 of the European Parliament and of the Council on freedom of movement for workers within the Union with regard to Romanian workers, Official Journal of the European Union, 22.12.2012, <http://eur-lex.europa.eu/JOHtml.do?uri=OJ:L:2012:356:SOM:EN:HTML> [8 de enero de 2013].

García, I. y Troncoso, D. (2011): “La inmigración en el mercado laboral español. ¿Qué ha cambiado entre 2007 y 2011? ”, Anuario de la Inmigración en España 2010. Barcelona, CIDOB, p. 210-251.

Gaspard, M. (1993) : "Revenus et niveaux de vie en Europe centrale et orientale et en ex URSS”, Le Courrier des Pays de l'Est, n ${ }^{\circ}$ 383, p. 4-14.

González-Enríquez, C. (2010): “Irregularity as a Rule”. In Triandafyllidou, Anna (ed.): Irregular Migration in Europe. Myths and Realities. Burlington, Asghate, p. 247-266.

Gordo, M. (2008): “La contratación en origen de rumanos para actividades agrícolas de temporada en España”, Cuadernos de Geografía, nº 84, p. 237-262.

Gualda, E. (2012): “Migración circular en tiempos de crisis. Mujeres de Europa del Este y africanas en la agricultura de Huelva”, Papers, 97/3, p. 613-640.

Gurak, D. y Caces, F. (1998): "Redes migratorias y la formación de sistemas de migración”. In Graciela Malgesini (comp.): Cruzando fronteras. Migraciones en el sistema mundial. Barcelona, Icaria, p. 75-110.

IOM (2008): Migration in Romania: A Country Profile 2008, Geneva, International Organization for Migration, Geneva (Switzerland) <http://publications.iom.int/bookstore/free/Romania_Profile2008.pdf> [22 de junio de 2012]. 
King, R. (2012): “Geography and Migration Studies: Retrospect and Prospect”, Population, Space and Place, $\mathrm{n}^{\circ}$ 18, p. 134-153.

Laparra, M. y Pérez, B. -coord.- (2012): Crisis y fractura social en Europa. Causas y efectos en España. Barcelona, Colección Estudios Sociales, Obra Social La Caixa.

Lhomel, E. (2004): “Roumanie 2003-2004, sur la dernière ligne droite?”, Le Courrier des Pays de l'Est, $\mathrm{n}^{\circ}$ 1044, p. 185-196.

Marcu, S. (2009): "Inmigrantes rumanas en el servicio doméstico y de cuidados de la Comunidad de Madrid: estudio cualitativo”, Estudios Geográficos, vol. LXX, $n^{\circ} 267$, p. 463-489.

Marcu, S. (2011): "Romanian Migration to the Community of Madrid (Spain): Patterns of Mobility and Return”, International Journal of Population Research, <http://www.hindawi.com/journals/ijpr/2011/258646/> [4 de octubre de 2012].

Marcu, S. (2013): "La movilidad transfronteriza de rumanos en España en tiempos de crisis”. Revista Internacional de Sociología, 71/1, pp. 115-141.

Massey, D. y García, F. (1987): "The social process of international migration”, Science, $\mathrm{n}^{\circ}$ 237: 733-738.

Menor, J. (2011): "La movilidad de los inmigrantes temporeros para las campañas agrícolas: el caso de los marroquíes durante la recogida de la aceituna en la provincia de Jaén”. In García, F. J. y Kressova, N. (coord.): Actas del I Congreso Internacional sobre Migraciones en Andalucía. Granada, Instituto de Migraciones, p. 543-558.

Muntele, I. (2003): "Migrations internacionales dans la Roumanie moderne et contemporaine”. In Diminescu, D. (dir): Visibles mais peu nombreux. Les circulations migratoires roumaines. París, Éditions de la Maison des Sciences de l'Homme, p. 33-48.

OBSERVATORIO DE LAS OCUPACIONES: Informe del mercado de trabajo de los extranjeros. Servicio Público de Empleo Estatal. Varios años. $<$ http://www.sepe.es/indiceObservatorio/> [16 de enero de 2013].

Pajares, M. (2007): Inmigrantes del Este. Procesos migratorios de los rumanos. Barcelona, Icaria.

Pajares, M. (2009): Inmigración y mercado de trabajo. Informe 2009. Madrid, Ministerio de Trabajo e Inmigración.

Pérez, F. y Serrano, L. (2008): "Los inmigrantes y el mercado de trabajo español: una aproximación económica”. In García, J. y Lacomba, J. -eds.-: La inmigración en la sociedad española. Barcelona, Ediciones Bellaterra, p. 157-203.

Piore, M. J. (1979): Birds of Passage. Migrant Labor and Industrial Societies. New York and Cambridge, Cambridge University Press.

Piore, M. J. (1983): "Los trabajadores extranjeros". In Michel J. Piore (comp.), Paro e inflación. Perspectivas institucionales y estructurales. Madrid, Alianza, p. 273-289.

Popescu, C. (2006): “Industrial restructuring”. In Balteanu, D. (coord.): Romania. Space, Society, Environment. Bucarest, Romanian Academy, p. 236-257. 
Potot, S. (2007): Vivre à l'Est, travailler à l'Ouest: les routes roumaines de l'Europe. París, l'Harmattan, 226 p.

Reyneri, E. y Fullin, G. (2011): "Labour market penalties of new immigrants in new and old receiving West European countries”, International Migration, vol. 49, p. 31-57.

Roig, M. y Recaño, J. (2012): "The Impact of the Global Financial Crisis on Migration to and Remittance Flows from Spain”. In Sirkeci, I.; Cohen, J. H. y Ratha, D. (eds.): Migration and Remittances during the global Financial Crisis and Beyond. Washington, D.C., World Bank, p. 255-269.

Sandu, D. -dir.- (2009): Comunităţi româneşti în Spania, Fundaţia Soros România, $<$ http://www.osf.ro/ro/comunicate_detaliu.php?comunicat=85\#> [14 de febrero de 2012].

Şerban, M. y Grigoraş, V.(2000): "The 'dogeni' from Teleorman at home and abroad. A study on circular migration to Spain”, Sociologie Româneasca, n 2, p. 92-120.

Şerban, M. y Voicu, B. (2010): "Romanian Migrants to Spain: In-or Outside the Migration Networks. A Matter of Time?” Revue d'Études Comparatives EstOuest, vol. 41, nº4, p. 97-124.

Simón, H.; Ramos, R. y Sanromá, E. (2011): “Occupational Mobility of Immigrants in a Low SKilled Economy. The Sapnish Case”, IZA Discussion Paper No. 5581, $<$ http://ftp.iza.org/dp5581.pdf> [17 de noviembre de 2012].

Sirkeci, I.; Cohen J. H. y Ratha, D. -eds.- (2012): Migration and Remittances during the global Financial Crisis and Beyond. Washington, D.C., World Bank.

Stoiciu, V.; Stanculescu, M.; Alexe, I. y Motoc, l. (2011): Impactul crizei economice asupra migratiei fortei de munca romanesti. Bucarest, Friedrich Ebert Foundation, <http://www.fes.ro/media/images/publications/Impactul_crizei.pdf > [22 de enero de 2013].

Terrón, A. (2004): "Spain”. In Niessen, J. and Schibel, Y. (eds.): International migration and relations with third countries: European and US approaches. Brussels, Migration Policy Group, < http://www.migpolgroup.org/publications_detail.php?id=123> [4 de enero de 2013].

Torres, F. (2011): La inserción de los inmigrantes. Luces y sombras de un proceso. Madrid, Talasa Ediciones, S.L.

Torres, F. y Gadea, M ${ }^{a}$ E. (2010): "Inserción laboral de los inmigrantes. Estructura etno-fragmentada y crisis económica. El caso del Campo de Cartagena (Murcia)", Sociología del Trabajo, $n^{\circ}$ 69, p. 73-94.

UNICEF (1999): Après la chute. L'impact humain de dix ans de transition. Florence, Fons des Nations Unies pour l'Enfance, Centre International pour le Développement de l'Enfant, <http://www.unicefirc.org/publications/pdf/apreslachute.pdf $>$ [9 de septiembre de 2012].

Viruela, R. (2002): "La nueva corriente inmigratoria de Europa del Este”. Cuadernos de Geografía, n ${ }^{\circ}$ 72, p. 231-258. 
Viruela, R. (2006): "Inmigrantes rumanos en España: aspectos territoriales y procesos de sustitución laboral”, Scripta Nova. Revista Electrónica de Geografía y Ciencias Sociales, vol. X, no 222, <http://www.ub.edu/geocrit/sn/sn-222.htm> [4 de diciembre de 2012]

Viruela, R. (2009): “Inserción laboral de los inmigrantes rumanos”. In Gordo, M. y Felicidades, J. (eds.): Explorando los contratos en origen en los campos españoles. Huelva, Universidad de Huelva, p. 211-231.

Viruela, R. (2010): "Movilidad geográfica de los rumanos (estructura territorial de las migraciones interiores en España)”, Empiria. Revista de Metodología de Ciencias Sociales, $\mathrm{n}^{\circ}$ 19, p. 157-181.

Viruela, R. (2011): “The Romanian Migrants in Spain. An Exceptional Migratory Flow”, International Review of Social Research, $\mathrm{n}^{\circ}$ 1, p. 31-59, $<$ http://www.irsr.eu/archive.html $>$ [16 de enero de 2013].

WORLD BANK (2002): The first Ten Years. Analysis and Lessons for Eastern Europe and the Former Soviet Union. Washington, D.C., World Bank, <http://siteresources.worldbank.org/ECAEXT/Resources/complete.pdf > [4 de octubre de 2012].

WORLD BANK (2010): Migration Data. Bilateral Migration Matrix 2010, $<$ http://go.worldbank.org/JITC7NYTT0> [24 de abril de 2012]. 